\title{
Erratum zu: Methoden zur Entwicklung modularer Produktfamilien
}

\author{
Dieter Krause · Nicolas Gebhardt
}

\section{Erratum zu:}

Kapitel 6: D. Krause, N. Gebhardt, Methodische Entwicklung modularer Produktfamilien, https://doi.org/10.1007/978-3-662-53040-5_6

Im Kapitel 6, Abbildung 6.26 Vorgehen der kostenbasierten Auswahl modularer Produktstrukturen wurde leider die Quellenangabe falsch wiedergegeben.

Die korrekte und einzige Quellenangabe für Abb. 6.26 lautet: „(Ripperda 2015)“.

Das aktualisierte Kapitel ist unter folgendem Link verfügbar:

https://doi.org/10.1007/978-3-662-53040-5_6 